\title{
Clinical History of the Theranostic Radionuclide Approach to Neuroendocrine Tumors and Other Types of Cancer: Historical Review Based on an Interview of Eric P. Krenning by Rachel Levine
}

\author{
Rachel Levine ${ }^{1}$ and Eric P. Krenning ${ }^{2}$ \\ ${ }^{1}$ Corporate Communications, Advanced Accelerator Applications, S.A., New York, New York; and ${ }^{2}$ Erasmus University Medical \\ Center (Erasmus MC), Rotterdam, The Netherlands
}

\begin{abstract}
In nuclear medicine, the term theranostics describes the combination of therapy and diagnostic imaging. In practice, this concept dates back more than 50 years; however, among the most successful examples of theranostics are peptide receptor scintigraphy and peptide receptor radionuclide therapy of neuroendocrine tumors. The development of these modalities through the radiolabeling of somatostatin analogs with various radionuclides has led to a revolution in patient management and established a foundation for expansion of the theranostic principle into other oncology indications. This article provides a review of the evolution and development of the theranostic radionuclide approach to the management of neuroendocrine tumors, as described by the inventor of this technique, Eric P. Krenning, in an interview with Rachel Levine.
\end{abstract}

Key Words: PRRT; neuroendocrine; somatostatin; PSMA; peptide

J Nucl Med 2017; 58:3S-9S

DOI: 10.2967/jnumed.116.186502

\footnotetext{
A

lthough the term theranostics was reported to be coined by John Funkhouser in 1998 (1) to describe a material that combines the modalities of therapy and diagnostic imaging, this basic principle had been applied to imaging and treating thyroid diseases for more than 50 years (2). In 1941, Saul Hertz was the first to use ${ }^{131}$ I therapeutically in patients with hyperthyroidism and later those with thyroid cancer (2). In 1951, the U.S. Food and Drug Administration (FDA) approved sodium iodide $\left({ }^{131} \mathrm{I}\right)$ for use in patients with thyroid disease. It was the first FDA-approved radiopharmaceutical (3).
}

\section{PEPTIDE RECEPTORS AND NEW THERANOSTIC APPLICATIONS}

Among the most successful examples of the theranostic concept in nuclear medicine are peptide receptor scintigraphy (PRS) and peptide receptor radionuclide therapy (PRRT) for imaging and treating cancer. These innovations were first used in patients with

Received Feb. 6, 2017; revision accepted Apr. 13, 2017.

For correspondence or reprints contact: Rachel Levine, Advanced Accelerator Applications, 350 Fifth Ave., Suite 6902, New York, NY 10118.

E-mail: rachel.levine@adacap.com

COPYRIGHT (c) 2017 by the Society of Nuclear Medicine and Molecular Imaging. mainly neuroendocrine tumors (NETs) $(4,5)$ in the late 1980s and early 1990s, although these acronyms were not published until 1994 (5).

The origination of PRS and PRRT date back to an endocrinology postdoctoral meeting of Erasmus University Medical Center (Erasmus MC), Rotterdam, The Netherlands, in 1985. Steven Lamberts presented slides with receptor autoradiograms obtained and originating from Jean Claude Reubi, who was, at that time, working at the Sandoz Research Institute in Basel, Switzerland. Using slices of tumor tissue obtained from patients with gastroenteropancreatic NETs (GEP-NETs), Reubi, Lamberts, and collaborator Larry Kvols (at the Mayo Clinic, Rochester, Minnesota, at that time) had demonstrated, for the first time, the presence of receptors for somatostatin on the surface of intestinal NET cells. This finding was crucial to identifying (one of) the mechanisms of action of octreotide, a somatostatin analog invented at the Sandoz Research Institute and first published in $1982(6,7)$. Reubi's team was using this analog coupled to the iodine isotope ${ }^{125} \mathrm{I}$ (8). Eric P. Krenning, an endocrinologist and then recently appointed head of nuclear medicine at Erasmus MC, was present at that meeting. Working daily with the isotopes ${ }^{123} \mathrm{I}$ and ${ }^{131} \mathrm{I}$ for the localization and treatment of thyroid cancer, Krenning instantly recognized the potential of radiolabeled peptides to localize and treat NETs in a clinical setting ("from bench to bedside"). Later that evening, at the usual social gathering after the scientific part of the meeting, Krenning started a discussion with chemists Theo Visser and Roel Docter regarding how to change the application of the somatostatin analog from in vitro receptor autoradiography to in vivo receptor scintigraphy by radiolabeling it with the 2 iodine isotopes frequently used in nuclear medicine, namely, ${ }^{123} \mathrm{I}$ and ${ }^{131} \mathrm{I}$.

\section{CHALLENGE OF RADIOLABELING}

After a period of trial and error (resulting in, "Eric, it is a nogo") during attempts to label the peptide with a radioiodine isotope appropriate for imaging in humans, Willem Bakker and Wout Breeman, chemists working in Krenning's department, made a final and crucial attempt. They ordered every available preparation of ${ }^{123}$ I from vendors worldwide and finally found a single, highspecific-activity preparation of ${ }^{123}$ I that enabled them to overcome the labeling challenge and succeed in producing a suitable radiolabeled somatostatin analog, ${ }^{123} \mathrm{I}$-labeled $\mathrm{Tyr}^{3}$-octreotide. In 1987, the surprising and exciting planar and SPECT images obtained of a GEP-NET patient with this new technique showed almost 
instantly the primary gastrinoma, an unknown metastasis in the Virchow node, and a known meningioma (Fig. 1). By 1990, $\left[{ }^{123} \mathrm{I}_{-} \mathrm{Tyr}^{3}\right]$ octreotide had been used in several hundreds of patients to localize carcinoid tumors, pancreatic endocrine tumors, and paragangliomas (9). Unfortunately, concentrated intestinal accumulation resulting from the high biliary excretion of ${ }^{123} \mathrm{I}$ hampered the interpretation of planar and SPECT images of lesions in the abdomen. This drawback was serious and provided evidence that a better agent was needed. Moreover, the high cost and limited availability of the highly specific form of ${ }^{123}$ I required to radiolabel the analog made it impractical.

\section{NEW SOLUTION EMERGES: ${ }^{111}$ IN-PENTETREOTIDE}

By 1990, Krenning's team, in cooperation with colleagues at Sandoz Research Institute (Janos Pless, Rainer Albert, Christian Bruns, Peter Marbach, and Barbara Stolz), had successfully developed ${ }^{111}$ In-pentetreotide (OctreoScan; Mallinckrodt). In 1993, Krenning's team published data on their experiences using ${ }^{111}$ In-pentetreotide imaging in more than 1,000 patients (10). This publication is now widely considered an important reference in nuclear medicine and is the most frequently cited paper from the European Journal of Nuclear Medicine. In 1994, the FDA approved ${ }^{111}$ In-pentetreotide as an imaging radiopharmaceutical, exclusively on the basis of results achieved in approximately 350 European patients because its sensitivity and specificity in patients with GEP-NETs were higher than those of CT or MRI. ${ }^{111}$ In-pentetreotide was the first peptide-based radiopharmaceutical ever approved.

Having established a simpler and more effective imaging technology for NETs (especially for abdominal imaging), the next logical step for Krenning and his team was to follow the model of radioiodine use in thyroid cancer and hyperthyroidism to create a theranostic agent. The team worked closely with Mallinckrodt Medical, Petten, The Netherlands, the company that had licensed and was actively marketing OctreoScan, to create PRRT using very high doses of the product. In 1992, using the specific physical characteristics of the Auger and conversion

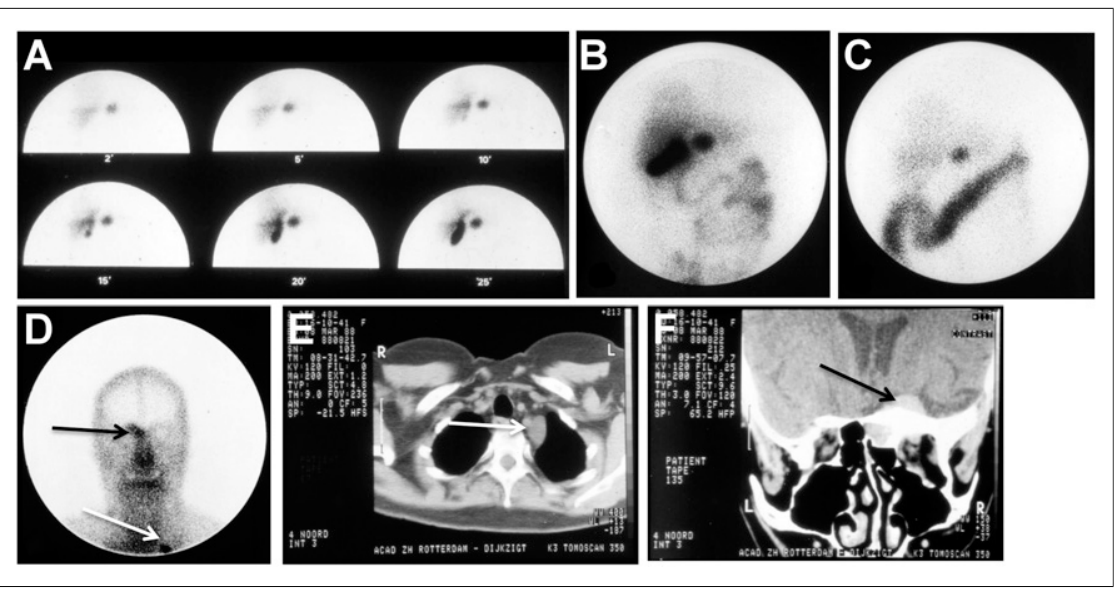

FIGURE 1. [123|-Tyr $\left.{ }^{3}\right]$ octreotide planar scintigraphy of gastrinoma in 1987. (A-D) Abdominal images show gallbladder and primary tumor at 2-25 min after injection $(A)$ and at $6 \mathrm{~h}(B)$ and $24 \mathrm{~h}(\mathrm{C})$ after injection, with prominent bowel accumulation, as well as unknown metastasis in Virchow node (white arrow) and known meningioma (black arrow) (D). (E and F) CT images show Virchow node $(\mathrm{E})$ and meningioma $(\mathrm{F})$. electrons of ${ }^{111} \mathrm{In}$, the Erasmus MC team successfully treated the first NET patient (with glucagonoma) with high doses of ${ }^{111}$ Inpentetreotide (5).

\section{NEXT STEPS FOR PRRT}

After a few years of PRRT experience with ${ }^{111}$ In-pentetreotide (Fig. 2) (11), it became clear that other radionuclides might be better suited for the regimen than ${ }^{111}$ In because its short tissue range resulted in relatively modest tumor shrinkage (based on anatomic imaging with CT/MRI). In addition, DOTA-chelated peptides, which could be more easily labeled with radioactive metals, also started becoming available (12-14).

In retrospect, Krenning observed, minimal shrinkage of tumors (based on CT/MRI) with the achievement of stable disease may not necessarily have been a less-than-optimal result because stable disease may indicate that fibrosis has replaced cancer-a distinction not made by CT/MRI. Such a distinction can be made only with functional imaging, such as PET. This observation is further supported by similar progression-free survival and overall survival data obtained from a comparison of GEP-NET patients with stable disease as a treatment outcome to patients with partial or complete remission as a treatment outcome (15).

Despite its seemingly limited impact on tumor shrinkage (based on CT/MRI), PRRT with ${ }^{111}$ In-pentetreotide did have an impressive positive effect on the quality of life of patients, including those with large tumors. Krenning observed that 2 wheelchairbound patients were able to walk again after this therapy and recalled a similarly impressive finding shared (written communication, March 18, 2007) by Richard Baum's group at Zentralklinik, Bad Berka, Germany, after ${ }^{90}$ Y PRRT treatment of a young boy with malignant paraganglioma. The overall improvement in the quality of life of patients after PRRT treatment was so significant that patients were demanding repeated treatments with ${ }^{111} \mathrm{In}$ pentetreotide (in the absence of an alternative treatment modality at the time), despite the acknowledged risk of developing myelodysplastic syndrome or leukemia. Indeed, a total of 50 patients received many cycles of ${ }^{111} \mathrm{In}$-pentetreotide in about $5 \mathrm{y}$ at Erasmus MC. Three of the 6 patients who received more than $100 \mathrm{GBq}$ $(2,700 \mathrm{mCi})$ (equivalent to 450 adult imaging doses) cumulatively developed myelodysplastic syndrome or leukemia at a mean bone marrow dose of about 3 Gy (11).

\section{DEVELOPMENT OF KIDNEY PROTECTION WITH LYSINE AND ARGININE}

With the introduction of ${ }^{90} \mathrm{Y}$ PRRT, it became apparent that measures to protect against renal uptake of the radionuclide were needed. After an initial publication on the protective properties of certain amino acids by Hammond et al. (16), Krenning, Marion de Jong, Edgar Rolleman, and Roelf Valkema started preclinical and clinical investigations to optimize kidney protection with the amino acids lysine and arginine during PRRT with somatostatin analogs. After significant testing in patients receiving ${ }^{111}$ In PRRT, optimal and safe doses (not inducing hyperkalemia) of 


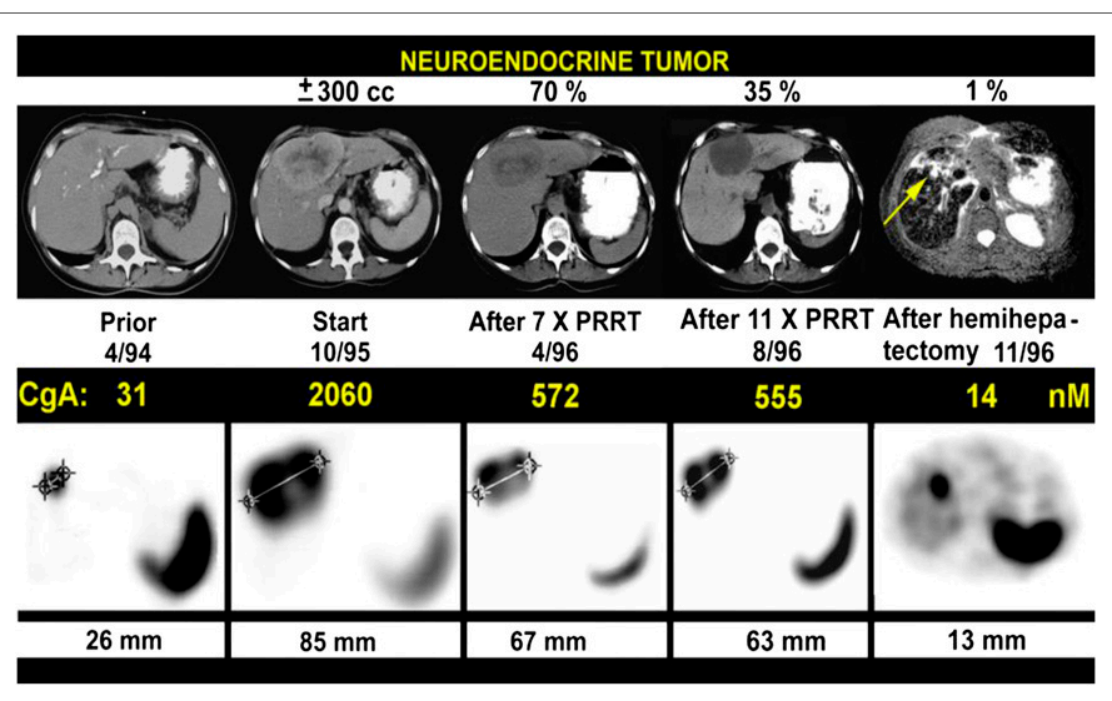

FIGURE 2. PRRT with very high doses $\left(7.4 \mathrm{GBq}\right.$ [200 $\mathrm{mCi}$ per cycle) of ${ }^{111} \mathrm{In}$-pentetreotide in patients with NETs in 1994-1996. Tumor shrinkage and tumor marker decline (as indicated by chromogranin $\mathrm{A}[\mathrm{CgA}]$ ) after 11 cycles were $65 \%-70 \%$ (top row); subsequent hemihepatectomy left behind small tumor of $9 \mathrm{~mm}$ at cutting edge. Top row shows CT (except for 11/96 [MRI]), and bottom row shows transverse slices from ${ }^{111}$ In-pentetreotide SPECT. (Adapted with permission of (11).)
${ }^{90}$ Y-labeled DOTATOC (by applying specific kidney and bone marrow radiation limits), to evaluate the effects of commercially available amino acid solutions on kidney protection, to measure the effect of the peptide mass on tumor accumulation, and to compare ${ }^{90}$ Y-labeled DOTATOC dosimetry with that of ${ }^{111}$ In-pentetreotide (18-22). The overall response rates obtained with ${ }^{90}$ Y-labeled DOTATOC PRRT at most of the European sites were indeed better than those obtained with ${ }^{111}$ In-pentetreotide; however, this increase in response rates came at the expense of higher renal toxicity.

\section{FIRST GALLIUM-LABELED PEPTIDE IMAGING}

In 1995 and early 1996, the Basel group, in cooperation with Heiner Bihl (Katharinenhospital, Stuttgart, Germany), imaged 12 patients with ${ }^{67} \mathrm{Ga}$-DOTATOC $\gamma$-camera imaging as a surrogate for ${ }^{68} \mathrm{Ga}$-DOTATOC PET. The clinical data were presented at the European Association of Nuclear the amino acids were achieved. The discovery of the role of megalin (a multiligand scavenger receptor in renal proximal tubules) in the mechanism of action of lysine facilitated this success (17). The Erasmus MC lysine-arginine formulation, which is still used worldwide today, contains $25 \mathrm{~g}$ of each of these amino acids in only a $1-\mathrm{L}$ volume. This low volume provides an advantage over the larger volumes of commercially available amino acid solutions with similar amounts of lysine and arginine being given to NET patients during a 4-h infusion. These patients often have heart valve abnormalities and thus are more prone to heart failure after receiving such a large fluid load in a short time. This specialized formulation is also an improvement over commercially available amino acid solutions because the latter tend to induce significant nausea and vomiting in patients more frequently.

\section{${ }^{90}{ }^{9}$-DOTA,TYR ${ }^{3}$ ]OCTREOTIDE ENTERS SCENE}

In 1997, Novartis, in Basel, Switzerland, launched a study of a new type of PRRT-PRRT with ${ }^{90}$ Y-labeled DOTA, Tyr $^{3}$-octreotide (DOTATOC, edotreotide, or OctreoTher [Novartis]) — in collaboration with Cliniques Universitaires St. Luc, Brussels, Belgium (Stanislas Pauwels, Francois Jamar, and Stefan Walrand); the University of New Mexico, Albuquerque, New Mexico (Larry Kvols); and Erasmus MC (Eric P. Krenning and Roelf Valkema). ${ }^{90} \mathrm{Y}$ was considered an alternative to ${ }^{111} \mathrm{In}$ because of its longer range of tissue penetration, which was hoped to have a greater impact on tumor shrinkage. The protocol for the study, named B151, was unique in that patients were required to undergo PET dosimetry through another trial protocol (B101) before receiving PRRT. The Brussels group successfully introduced ${ }^{86}$ Y-labeled DOTATOC PET dosimetry in the B101 study (18-22), whereas the other European centers used ${ }^{111} \mathrm{In}$-labeled DOTATOC as a ${ }^{90} \mathrm{Y}$ surrogate for dosimetry. The isotopes ${ }^{86} \mathrm{Y}$ and ${ }^{90} \mathrm{Y}$ are positron- and $\beta$-emitters, respectively.

The objectives of the ${ }^{86}$ Y-labeled DOTATOC PET study were to assess the pharmacokinetics and biodistribution of this radiopeptide, to estimate the individual maximum tolerated doses of
Medicine annual meeting in 1996 and were included in the highlight lecture (23).

\section{${ }^{90}$ Y PRRT CONTINUES TO THRIVE}

In the late 1990s and early 2000s, "early adopters" of PRRT were successfully using ${ }^{90} \mathrm{Y}$ coupled to various somatostatin analogs $(13,24-27)$. A clinical study with ${ }^{90}$ Y-DOTATOC was started in Basel in June 1996; soon thereafter, the study became a collaboration with the European Institute of Oncology, Milan, Italy (Giovanni Paganelli and Lisa Bodei), and the University Hospital Frankfurt, Frankfurt am Main, Germany (Richard Baum). In 1998, Otte et al. (28) reported the use of ${ }^{90}$ Y-labeled DOTATOC in the treatment of 10 patients with different somatostatin receptor-positive tumors. In 2001, the results of a phase 2 study of ${ }^{90}$ Y-DOTATOC in 41 patients with GEP-NETs and bronchial tumors demonstrated an overall response rate of $24 \%$ and a significant reduction in carcinoid syndrome in $83 \%$ of the patients (26). In 2011, the results of a study by Imhof et al. of 1,109 patients showed a morphologic response in $34.1 \%$ of the patients, longer survival in $79 \%$ of the patients, and grade 4 or 5 permanent renal toxicity in $9.2 \%$ of the patients (29).

The primary observed disadvantage of ${ }^{90} \mathrm{Y}$ PRRT was renal toxicity. ${ }^{90} \mathrm{Y}$ PRRT resulted in renal failure in patients when performed without kidney protection, although some renal toxicity was still observed even with the administration of amino acids for kidney protection (30-32). These findings led to the conclusion that renal protection is imperative for any PRRT with $\beta$-emitting radionuclides. Therefore, even the first patients receiving $\left[{ }^{177} \mathrm{Lu}-\mathrm{DOTA}, \mathrm{Tyr}^{3}\right]$ octreotate PRRT in 2000 were given an amino acid solution for renal protection.

\section{LU PRRT IS DEVELOPED}

In 1998 (33), a unique collaboration named Specific Peptides for Imaging and Radio Isotope Therapy (S.P.I.R.I.T.) was established by several intercontinental universities: Cliniques Universitaires 
St. Luc, Brussels, Belgium (Stanislas Pauwels and Francois Jamar); University of Berne, Berne, Switzerland (Jean Claude Reubi); University Hospital Basel, Basel, Switzerland (Helmut Maecke); Erasmus MC, Rotterdam, The Netherlands (Eric Krenning, Marion de Jong, and Theo Visser); University of New Mexico, Albuquerque, New Mexico (Larry Kvols); and Mallinckrodt Medical/Covidien, Petten, The Netherlands, and St. Louis, Missouri (Jack Erion, Ananth Srinivasan, Joe Bugaj, Michelle Schmidt, Jean-Luc Vanderheyden, and Geert Ensing). The goal was to develop marketable radiopharmaceuticals using targeting peptides and peptidelike molecules to deliver diagnostic or therapeutic medical doses to specific sites within the body.

One of the peptides originating from this network was $\left[{ }^{177} \mathrm{Lu}\right.$-DOTA, $\left.\mathrm{Tyr}^{3}\right]$ octreotate (LuTate or ${ }^{177} \mathrm{Lu}$-DOTATATE), an investigational therapy invented by the Mallinckrodt Medical researchers (14). The first clinical studies with $\left[{ }^{177} \mathrm{Lu}-\mathrm{DOTA}, \mathrm{Tyr}^{3}\right]$ octreotate started in 2000 in Rotterdam, The Netherlands, and involved a prospectively designed clinical protocol that later formed the basis of a multinational phase 3 trial named NETTER-1 (34).

In 2003, a study of $\left[{ }^{177} \mathrm{Lu}-\mathrm{DOTA}, \mathrm{Tyr}^{3}\right]$ octreotate therapy in 35 patients with GEP-NETs demonstrated complete remission in 1 patient (3\%), partial remission in 12 patients $(35 \%)$, stable disease in 14 patients $(41 \%)$, and progressive disease in 7 patients $(21 \%)$, including 3 patients who died during the treatment period (35). In 2005 and 2008, Kwekkeboom et al. published data illustrating tumor remission in high percentages of 131 and 310 patients, respectively, with metastasized or inoperable GEP-NETs treated with $\left[{ }^{177} \mathrm{Lu}\right.$-DOTA, Tyr $\left.{ }^{3}\right]$ octreotate $(36,37)$, including improvements in various aspects of quality of life $(38,39)$.

Clinicians at Erasmus MC were soon treating patients from countries all over the world, including patients from Europe, the United States, Brazil, Pakistan, and Australia. By August 2006, the Erasmus MC team (Dik Kwekkeboom, Jaap Teunissen, Boen Kam, and many others) had performed more than 1,750 treatments with $\left[{ }^{177} \mathrm{Lu}\right.$-DOTA, Tyr ${ }^{3}$ ]octreotate in more than 500 patientsand not only those with classic NETs $(40,41)$. Over the years, that number has increased to more than 1,500 patients, even though $\left[{ }^{177} \mathrm{Lu}\right.$-DOTA, Tyr $\left.{ }^{3}\right]$ octreotate has not yet been approved by regulatory authorities. Such enormous referral from foreign countries also took place in Basel, Bad Berka, and Milan; treatment with $\left[{ }^{177} \mathrm{Lu}\right.$-DOTA, $\left.\mathrm{Tyr}^{3}\right]$ octreotate in the United States started in 2013 (42).

After more than 15 y of experience with up to $29.6 \mathrm{GBq}(800$ $\mathrm{mCi}$ ) of cumulative administered doses of $\left[{ }^{177} \mathrm{Lu}-\mathrm{DOTA}, \mathrm{Tyr}^{3}\right]$ octreotate, Erasmus MC clinicians concluded that routine individual dosimetry did not enhance the safety of a single patient, as long as a strict clinical protocol with careful monitoring and control of bone marrow function was followed during PRRT. In addition, overall, there was no observed dose-response effect on serious (permanent) bone marrow toxicity, and it was believed to be unlikely that the widely used bone marrow limit of 2 Gy had any validity with regard to this radioligand (43). Finally, this experience also demonstrated that PRRT with $\left[{ }^{177} \mathrm{Lu}-\mathrm{DOTA}, \mathrm{Tyr}^{3}\right]$ octreotate, administered in conjunction with appropriate amounts of amino acids for kidney protection, had virtually no renal toxicity (44). In retrospect, Krenning noted, the cumulative dose initially selected in 2000 appeared to be correct-not surprisingly, however-considering that it was based on the global experience of more than 50 years of safe application of similar cumulative doses of ${ }^{131} \mathrm{I}$ for the therapy of thyroid cancer and that ${ }^{177} \mathrm{Lu}$ and ${ }^{131}$ I share many physical characteristics (30).

In 2001, BioSynthema Inc. was founded in St. Louis, Missouri (Jack Erion, Henk van Rossem, Mary Palank and Eric Krenning), as a spinoff of the S.P.I.R.I.T. collaboration to discover and develop pharmaceuticals targeting cell surface receptors overexpressed in cancer cells. In 2007, Covidien and BioSynthema Inc. signed exclusive agreements to develop cancer therapy with $\left[{ }^{177} \mathrm{Lu}-\mathrm{DOTA}, \mathrm{Tyr}^{3}\right]$ octreotate (45). In 2010, BioSynthema Inc. was acquired by Advanced Accelerator Applications, S.A., SaintGenis-Pouilly, France, a radiopharmaceutical company. With the support of Advanced Accelerator Applications, good manufacturing process-compliant manufacturing of $\left[{ }^{177} \mathrm{Lu}-\mathrm{DOTA}, \mathrm{Tyr}^{3}\right]$ octreotate was established, a regulatory pathway was negotiated with the FDA and the European Medicines Agency, and a pivotal multinational phase 3 study (NETTER-1) was conducted at 41 global sites.

By 2015, the NETTER-1 study had met its primary endpoint of assessing progression-free survival, demonstrating that $\left[{ }^{177} \mathrm{Lu}-\mathrm{DOTA}, \mathrm{Tyr}^{3}\right]$ octreotate significantly improved progressionfree survival compared with octreotide acetate injection (Sandostatin LAR; Novartis; $60 \mathrm{mg}$ ) in patients with advanced midgut NETs (34). In January 2017, the results of this phase 3 trial of $\left[{ }^{177} \mathrm{Lu}-\mathrm{DOTA}, \mathrm{Tyr}^{3}\right]$ octreotate in patients with midgut NETs were published in the New England Journal of Medicine (34). A new drug application and a marketing authorization application for $\left[{ }^{177} \mathrm{Lu}-\mathrm{DOTA}{ }^{0}, \mathrm{Tyr}^{3}\right]$ octreotate are currently under review with the FDA and the European Medicines Agency, and more than 1,600 NET patients have received treatment with $\left[{ }^{177} \mathrm{Lu}-D O T A^{0}\right.$, $\mathrm{Tyr}^{3}$ ]octreotate under compassionate use and named patient programs sponsored by Advanced Accelerator Applications in 11 countries.

Krenning holds the opinion that the results of the NETTER-1 trial validate previously published phase 2 trial data, making prospective phase 2 trials more impactful than generally thought in oncology. His interpretation is that the theranostic approach ("PRS positivity means PRRT feasibility"), as discussed here, is completely different from the general practice of chemotherapy. His hope is that future prospective phase 2 PRRT trials for other malignancies that express high levels of targetable peptide receptors, such as (castration-resistant) prostate cancer and breast cancer, may be sufficient for regulatory approval $(46,47)$. To this end, approximately 15 different peptides $(4,10,48-54)$ were investigated in humans at Erasmus MC between 1987 and 2009, and various different peptides and developments exploring the potential utility of PRRT in oncology and other diseases have been reported since then (see the following text).

\section{FUTURE OF THERANOSTICS}

The use of ${ }^{90} \mathrm{Y}$ and ${ }^{177} \mathrm{Lu}$, as single agents or in combination, for PRRT continues in several centers throughout Europe because animal studies have suggested that larger tumors respond better to ${ }^{90} \mathrm{Y}$ PRRT and smaller ones respond better to ${ }^{177} \mathrm{Lu}$ PRRT. Unfortunately, the animal tumor model used is not representative of the nature of tumors in humans (heterogeneous vs. homogeneous distributions of somatostatin receptors). Additionally, there are currently no randomized trial data comparing the combination of ${ }^{90} \mathrm{Y}$ PRRT and ${ }^{177} \mathrm{Lu}$ PRRT with ${ }^{177} \mathrm{Lu}$ PRRT alone, leaving 
the actual benefit of this combination of radionuclides in humans with GEP-NETs unknown, although potential efficacy has been reported $(55,56)$.

Newer trends include combinations of $\left[{ }^{177} \mathrm{Lu}-\mathrm{DOTA}^{0}, \mathrm{Tyr}^{3}\right]$ octreotate therapy with chemotherapy, targeted agents, or immunotherapies. In 2007, the first randomized phase 3 trial comparing the combination of ${ }^{177}$ Lu PRRT and capecitabine (Xeloda; Genentech), an oral chemotherapy agent, with ${ }^{177}$ Lu PRRT alone was started at Erasmus MC, with data expected in 2017 (57). Much experience and success with this approach have been obtained in Australia, where combination treatment with PRRT and chemotherapy is called peptide receptor chemoradionuclide therapy (58-60).

PRS and PRRT have gained popularity among NET specialists worldwide as theranostic approaches for their patients, although until the Society of Nuclear Medicine and Molecular Imaging and the European Neuroendocrine Tumor Society published guidelines for their use, there were few standardized clinical practices for the administration and implementation of these procedures or the evaluation of patient progress $(61,62)$.

In parallel with the advances in PRRT, investigators have been working on new ways to improve ${ }^{111} \mathrm{In}$-pentetreotide, the longstanding standard of care in PRS by SPECT (63). These new developments are primarily supported by the introduction of hybrid PET/CT cameras and ${ }^{68} \mathrm{Ga}$ generators. The recent approvals by the FDA and the European Medicines Agency of [ ${ }^{68} \mathrm{Ga}$-DOTA,Tyr $\left.{ }^{3}\right]$ octreotate and edotreotide for the localization of NETs by PET/CT (64) have already significantly changed the field of NET imagingmore than 20 years after the approval of ${ }^{111}$ In-pentetreotide-and paved the way for additional theranostic pairings using ${ }^{68} \mathrm{Ga}$ imaging and ${ }^{90} \mathrm{Y}$ or ${ }^{177} \mathrm{Lu}$ PRRT.

For example, the implementation of radiolabeled compounds targeting prostate-specific membrane antigen (PSMA) for both diagnostic and therapeutic applications is considered to be a milestone in the management of patients with castration-resistant prostate cancer $(46,47)$. The observation of frequent, persistent PSMA expression in such patients has provided the rationale for the recent introduction of PSMA radioligand therapy, with very promising initial results $(46,65)$.

Other recent developments include somatostatin antagonists with surprisingly higher levels of binding to NET lesions than classic agonists (66), pansomatostatin radioligands for multiple sst1-sst5 tumor targeting $(67,68)$, and the use of specific enzyme inhibitors as radiopeptide escorts promoting tumor targeting (69).

One final innovation in the theranostic paradigm is the development of the NETest, a gene transcript measure, which is of interest as a possible predictor of PRRT outcome (70). It is hoped that such a test also may act as a prognostic factor for the induction of myelodysplastic syndrome or leukemia by PRRT (occurring in $\sim 2 \%$ of patients) because these disorders do not seem to be directly related to the bone marrow impact of current clinical PRRT regimens.

\section{CONCLUSION}

In looking back over the past 30 years of theranostic development and progress, Krenning emphasized the importance of teamwork, collaboration between academia and industry, and the lesson of perseverance. He hopes that the success of the NETTER1 study and the potential approval of $\left[{ }^{177} \mathrm{Lu}-\mathrm{DOTA}^{0}, \mathrm{Tyr}^{3}\right]$ octreotate by regulatory authorities will translate into a breakthrough of support for the further investigation of peptides for use in diagnostics and PRRT for a wide range of cancer types. He also hopes that the long time and enormous amount of energy he spent exploring PRRT for NETs are not representative of the effort that will be required to develop PRRT for other cancers. According to Krenning, "Many lessons have been learned from the development of PRS and PRRT, which can be applied going forward. The success of NETTER-1 and enormous support from industry over the past 5 years has made it possible to gain worldwide attention for PRS and PRRT in various medical disciplines."

\section{DISCLOSURE}

Both authors are shareholders of Advanced Accelerator Applications, and Rachel Levine is an employee of Advanced Accelerator Applications. No other potential conflict of interest relevant to this article was reported.

\section{REFERENCES}

1. PharmaNetics and Aventis Pharmaceuticals announce filing of $510 \mathrm{~K}$ application for enoxaparin test [press release]. Evaluate website; October 9, 2001. http://www. evaluategroup.com/Universal/View.aspx ?type $=$ Story\&id=13343. Accessed May 23, 2017.

2. Silberstein EB. Radioiodine: the classic theranostic agent. Semin Nucl Med. 2012;42:164-170.

3. Historical timeline: important moments in the history of nuclear medicine. Society of Nuclear Medicine and Molecular Imaging website. http://www. snmmi.org/AboutSNMMI/Content.aspx?ItemNumber=4175. Accessed May 23, 2017.

4. Krenning EP, Bakker WH, Breeman WA, et al. Localisation of endocrinerelated tumours with radioiodinated analogue of somatostatin. Lancet. 1989; $1: 242-244$.

5. Krenning EP, Kooij PP, Bakker WH, et al. Radiotherapy with a radiolabeled somatostatin analogue, $\left[{ }^{111} \mathrm{In}-\mathrm{DTPA}-\mathrm{D}-\mathrm{Phe}^{1}\right]$-octreotide: a case history. Ann $\mathrm{N}$ Y Acad Sci. 1994;733:496-506.

6. Bauer W, Briner U, Doepfner W, et al. SMS 201-995: a very potent and selective octapeptide analogue of somatostatin with prolonged action. Life Sci. 1982;31: 1133-1140.

7. Marbach P, Bauer W, Bodmer D, et al. Discovery and development of somatostatin agonists. Pharm Biotechnol. 1998;11:183-209.

8. Reubi JC, Hacki WH, Lamberts SW. Hormone-producing gastrointestinal tumors contain a high density of somatostatin receptors. J Clin Endocrinol Metab. 1987;65:1127-1134.

9. Lamberts SW, Bakker WH, Reubi JC, Krenning EP. Somatostatin-receptor imaging in the localization of endocrine tumors. N Engl J Med. 1990;323: 1246-1249.

10. Krenning EP, Kwekkeboom DJ, Bakker WH, et al. Somatostatin receptor scintigraphy with [ [111 In-DTPA-D-Phe $\left.{ }^{1}\right]-$ and [ $\left.{ }^{123} \mathrm{I}_{-}-\mathrm{Tyr}^{3}\right]$-octreotide: the Rotterdam experience with more than 1000 patients. Eur J Nucl Med. 1993; 20:716-731.

11. Valkema R, De Jong M, Bakker WH, et al. Phase I study of peptide receptor radionuclide therapy with [In-DTPA] octreotide: the Rotterdam experience. Semin Nucl Med. 2002;32:110-122.

12. Albert R, Smith-Jones P, Stolz B, et al. Direct synthesis of [DOTA-DPhe ${ }^{1}$ ]octreotide and [DOTA-DPhe ${ }^{1}, \mathrm{Tyr}^{3}$ ]-octreotide (SMT487): two conjugates for systemic delivery of radiotherapeutical nuclides to somatostatin receptor positive tumors in man. Bioorg Med Chem Lett. 1998;8:1207-1210.

13. Otte A, Jermann E, Behe M, et al. DOTATOC: a powerful new tool for receptormediated radionuclide therapy. Eur J Nucl Med. 1997;24:792-795.

14. Erion JL, Bugaj JE, Schmidt MA, Wilhelm RR, Srinivasan A. High radiotherapeutic efficacy of [Lu-177]-DOTA-Y3-octreotate in a rat tumor model [abstract]. J Nucl Med. 1999;40(suppl):223p.

15. van Vliet EI, Krenning EP, Teunissen JJ, Bergsma H, Kam BL, Kwekkeboom DJ. Comparison of response evaluation in patients with gastroenteropancreatic and thoracic neuroendocrine tumors after treatment with $\left[{ }^{177} \mathrm{Lu}-\mathrm{DOTA}^{0}, \mathrm{Tyr}^{3}\right]$ octreotate. J Nucl Med. 2013;54:1689-1696. 
16. Hammond PJ, Wade AF, Gwilliam ME, et al. Amino acid infusion blocks renal tubular uptake of an indium-labelled somatostatin analogue. $\mathrm{Br} J$ Cancer. 1993;67:1437-1439.

17. Melis M, Krenning EP, Bernard BF, Barone R, Visser TJ, de Jong M. Localisation and mechanism of renal retention of radiolabelled somatostatin analogues. Eur J Nucl Med Mol Imaging. 2005;32:1136-1143.

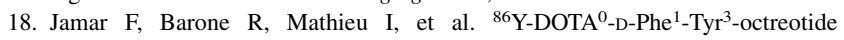
(SMT487): a phase 1 clinical study - pharmacokinetics, biodistribution and renal protective effect of different regimens of amino acid co-infusion. Eur J Nucl Med Mol Imaging. 2003;30:510-518.

19. Barone R, Borson-Chazot F, Valkema R, et al. Patient-specific dosimetry in predicting renal toxicity with ${ }^{90}$ Y-DOTATOC: relevance of kidney volume and dose rate in finding a dose-effect relationship. J Nucl Med. 2005;46(suppl 1): 99S-106S.

20. Pauwels S, Barone R, Walrand S, et al. Practical dosimetry of peptide receptor radionuclide therapy with ${ }^{90} \mathrm{Y}$-labeled somatostatin analogs. J Nucl Med. 2005; 46(suppl 1):92S-98S.

21. Barone R, Walrand S, Konijnenberg M, et al. Therapy using labelled somatostatin analogues: comparison of the absorbed doses with ${ }^{111}$ In-DTPA-D-Phe ${ }^{1}$ octreotide and yttrium-labelled DOTA-D-Phe ${ }^{1}-\mathrm{Tyr}^{3}$-octreotide. Nucl Med Commun. 2008;29:283-290.

22. Walrand S, Flux GD, Konijnenberg MW, et al. Dosimetry of yttrium-labelled radiopharmaceuticals for internal therapy: ${ }^{86} \mathrm{Y}$ or ${ }^{90} \mathrm{Y}$ imaging? Eur J Nucl Med Mol Imaging. 2011;38(suppl 1):S57-S68.

23. Delaloye AB. Highlights of the annual meeting of the European Association of Nuclear Medicine: Copenhagen 1996-nuclear medicine 100 years after the discovery of radioactivity. Eur J Nucl Med. 1997;24:219-232.

24. Leimer M, Kurtaran A, Smith-Jones P, et al. Response to treatment with yttrium 90-DOTA-lanreotide of a patient with metastatic gastrinoma. J Nucl Med. 1998;39:2090-2094.

25. Paganelli G, Zoboli S, Cremonesi M, Macke HR, Chinol M. Receptor-mediated radionuclide therapy with ${ }^{90} \mathrm{Y}$-DOTA-D-Phe ${ }^{1}-\mathrm{Tyr}^{3}$-octreotide: preliminary report in cancer patients. Cancer Biother Radiopharm. 1999;14:477-483.

26. Waldherr C, Pless M, Maecke HR, Haldemann A, Mueller-Brand J. The clinical value of $\left[{ }^{90} \mathrm{Y}-\mathrm{DOTA}\right]-\mathrm{D}-\mathrm{Phe}^{1}-\mathrm{Tyr}^{3}$-octreotide $\left({ }^{90} \mathrm{Y}\right.$-DOTATOC) in the treatment of neuroendocrine tumours: a clinical phase II study. Ann Oncol. 2001;12:941945.

27. Baum RP, Kulkarni HR, Carreras C. Peptides and receptors in image-guided therapy: theranostics for neuroendocrine neoplasms. Semin Nucl Med. 2012; 42:190-207.

28. Otte A, Mueller-Brand J, Dellas S, Nitzsche EU, Herrmann R, Maecke HR. Yttrium-90-labelled somatostatin-analogue for cancer treatment. Lancet. 1998; 351:417-418.

29. Imhof A, Brunner P, Marincek N, et al. Response, survival, and long-term toxicity after therapy with the radiolabeled somatostatin analogue [ $\left.{ }^{90} \mathrm{Y}-\mathrm{DOTA}\right]-$ TOC in metastasized neuroendocrine cancers. J Clin Oncol. 2011;29:24162423.

30. Cybulla M, Weiner SM, Otte A. End-stage renal disease after treatment with ${ }^{90}$ Y-DOTATOC. Eur J Nucl Med. 2001;28:1552-1554.

31. Bodei L, Cremonesi M, Ferrari M, et al. Long-term evaluation of renal toxicity after peptide receptor radionuclide therapy with ${ }^{90}$ Y-DOTATOC and ${ }^{177} \mathrm{Lu}-$ DOTATATE: the role of associated risk factors. Eur J Nucl Med Mol Imaging. 2008;35:1847-1856.

32. Bodei L, Kidd M, Paganelli G, et al. Long-term tolerability of PRRT in 807 patients with neuroendocrine tumours: the value and limitations of clinical factors. Eur J Nucl Med Mol Imaging. 2015;42:5-19.

33. Mallinckrodt sponsoring worldwide radiopharmaceutical collaboration with top academic researchers [press release]. Evaluate website; updated April 27, 1998. http://www.evaluategroup.com/Universal/View.aspx?type $=$ Story\&id=93485. Accessed May 23, 2017.

34. Strosberg J, El-Haddad G, Wolin E, et al. Phase 3 trial of ${ }^{177}$ Lu-dotatate for midgut neuroendocrine tumors. N Engl J Med. 2017;376:125-135.

35. Kwekkeboom DJ, Bakker WH, Kam BL, et al. Treatment of patients with gastro-entero-pancreatic (GEP) tumours with the novel radiolabelled somatostatin analogue $\left[{ }^{177} \mathrm{Lu}_{-\mathrm{DOTA}}{ }^{0}, \mathrm{Tyr}^{3}\right]$ octreotate. Eur J Nucl Med Mol Imaging. 2003;30:417-422.

36. Kwekkeboom DJ, Teunissen JJ, Bakker WH, et al. Radiolabeled somatostatin analog $\left[{ }^{177} \mathrm{Lu}-\mathrm{DOTA}^{0}, \mathrm{Tyr}^{3}\right]$ octreotate in patients with endocrine gastroenteropancreatic tumors. J Clin Oncol. 2005;23:2754-2762.

37. Kwekkeboom DJ, de Herder WW, Kam BL, et al. Treatment with the radiolabeled somatostatin analog $\left[{ }^{177} \mathrm{Lu}-\mathrm{DOTA}{ }^{0}, \mathrm{Tyr}^{3}\right]$ octreotate: toxicity, efficacy, and survival. J Clin Oncol. 2008;26:2124-2130.
38. Teunissen JJ, Kwekkeboom DJ, Krenning EP. Quality of life in patients with gastroenteropancreatic tumors treated with $\left[{ }^{177} \mathrm{Lu}-\mathrm{DOTA}^{0}, \mathrm{Tyr}^{3}\right]$ octreotate. J Clin Oncol. 2004;22:2724-2729.

39. Khan S, Krenning EP, van Essen M, Kam BL, Teunissen JJ, Kwekkeboom DJ. Quality of life in 265 patients with gastroenteropancreatic or bronchial neuroendocrine tumors treated with $\left[{ }^{177} \mathrm{Lu}-\mathrm{DOTA}^{0}, \mathrm{Tyr}^{3}\right]$ octreotate. J Nucl Med. 2011;52:1361-1368.

40. Teunissen JJ, Kwekkeboom DJ, Kooij PP, Bakker WH, Krenning EP. Peptide receptor radionuclide therapy for non-radioiodine-avid differentiated thyroid carcinoma. J Nucl Med. 2005;46(suppl 1):107S-114S.

41. van Essen M, Krenning EP, Kooij PP, et al. Effects of therapy with $\left[{ }^{177} \mathrm{Lu}-\mathrm{DOTA}{ }^{0}, \mathrm{Tyr}^{3}\right]$ octreotate in patients with paraganglioma, meningioma, small cell lung carcinoma, and melanoma. J Nucl Med. 2006;47:15991606.

42. Delpassand ES, Samarghandi A, Zamanian S, et al. Peptide receptor radionuclide therapy with ${ }^{177} \mathrm{Lu}$-DOTATATE for patients with somatostatin receptorexpressing neuroendocrine tumors: the first US phase 2 experience. Pancreas. 2014;43:518-525.

43. Bergsma H, Konijnenberg MW, Kam BL, et al. Subacute haematotoxicity after PRRT with ${ }^{177} \mathrm{Lu}$-DOTA-octreotate: prognostic factors, incidence and course. Eur J Nucl Med Mol Imaging. 2016;43:453-463.

44. Bergsma H, Konijnenberg MW, van der Zwan WA, et al. Nephrotoxicity after PRRT with ${ }^{177}$ Lu-DOTA-octreotate. Eur J Nucl Med Mol Imaging. 2016;43: 1802-1811.

45. Covidien and BioSynthema sign exclusive agreements for cancer therapy technology [news release]. Covidien website; updated October 15, 2007. http://news. covidien.com/phoenix.zhtml?c=216712\&p=irol-newsArticle_print\&ID=1910894. Accessed May 23, 2017.

46. Pfestroff A, Luster M, Jilg CA, et al. Current status and future perspectives of PSMA-targeted therapy in Europe: opportunity knocks. Eur J Nucl Med Mol Imaging. 2015;42:1971-1975.

47. Chatalic KL, Kwekkeboom DJ, de Jong M. Radiopeptides for imaging and therapy: a radiant future. $J$ Nucl Med. 2015;56:1809-1812.

48. van Hagen PM, Breeman WA, Reubi JC, et al. Visualization of the thymus by substance P receptor scintigraphy in man. Eur J Nucl Med. 1996;23:15081513 .

49. Breeman WA, van Hagen PM, Kwekkeboom DJ, Visser TJ, Krenning EP. Somatostatin receptor scintigraphy using $\left[{ }^{111}\right.$ In-DTPA0]RC-160 in humans: a comparison with [ ${ }^{111}$ In-DTPA $\left.{ }^{0}\right]$ octreotide. Eur J Nucl Med. 1998;25:182186.

50. de Jong M, Bakker WH, Bernard BF, et al. Preclinical and initial clinical evaluation of ${ }^{111}$ In-labeled nonsulfated CCK8 analog: a peptide for CCK-B receptor-targeted scintigraphy and radionuclide therapy. J Nucl Med. 1999; 40:2081-2087.

51. Kwekkeboom DJ, Bakker WH, Kooij PP, et al. Cholecystokinin receptor imaging using an octapeptide DTPA-CCK analogue in patients with medullary thyroid carcinoma. Eur J Nucl Med. 2000;27:1312-1317.

52. Kwekkeboom DJ, Bakker WH, Kooij PP, et al. $\left[{ }^{177}{ }^{L u-D O T A}{ }^{0}\right.$ Tyr $\left.^{3}\right]$ octreotate: comparison with $\left[{ }^{111}\right.$ In-DTPA $\left.{ }^{0}\right]$ octreotide in patients. Eur J Nucl Med. 2001;28: 1319-1325.

53. Breeman WA, Fröberg AC, de Blois E, et al. Optimised labeling, preclinical and initial clinical aspects of CCK-2 receptor-targeting with 3 radiolabeled peptides. Nucl Med Biol. 2008;35:839-849.

54. Valkema R, Pauwels S, Kvols LK, et al. Survival and response after peptide receptor radionuclide therapy with $\left[{ }^{90} \mathrm{Y}\right.$-DOTA $\left.{ }^{0}, \mathrm{Tyr}^{3}\right]$ octreotide in patients with advanced gastroenteropancreatic neuroendocrine tumors. Semin Nucl Med. 2006; 36:147-156.

55. Kunikowska J, Krolicki L, Hubalewska-Dydejczyk A, Mikolajczak R, Sowa-Staszczak A, Pawlak D. Clinical results of radionuclide therapy of neuroendocrine tumours with ${ }^{90}$ Y-DOTATATE and tandem ${ }^{90} \mathrm{Y} /{ }^{177} \mathrm{Lu}$-DOTATATE: which is a better therapy option? Eur J Nucl Med Mol Imaging. 2011;38: 1788-1797.

56. Seregni E, Maccauro M, Chiesa C, et al. Treatment with tandem $\left[{ }^{90} \mathrm{Y}\right] \mathrm{DOTA}-\mathrm{TATE}$ and $\left[{ }^{177} \mathrm{Lu}\right]$ DOTA-TATE of neuroendocrine tumours refractory to conventional therapy. Eur J Nucl Med Mol Imaging. 2014;41:223-230.

57. van Essen M, Krenning EP, Kam BL, de Herder WW, van Aken MO, Kwekkeboom DJ. Report on short-term side effects of treatments with ${ }^{177} \mathrm{Lu}$-octreotate in combination with capecitabine in seven patients with gastroenteropancreatic neuroendocrine tumours. Eur J Nucl Med Mol Imaging. 2008;35:743-748.

58. Claringbold PG, Turner JH. Pancreatic neuroendocrine tumor control: durable objective response to combination ${ }^{177} \mathrm{Lu}$-octreotate-capecitabinetemozolomide radiopeptide chemotherapy. Neuroendocrinology. 2016;103: $432-439$. 
59. Kong G, Thompson M, Collins M, et al. Assessment of predictors of response and long-term survival of patients with neuroendocrine tumour treated with peptide receptor chemoradionuclide therapy (PRCRT). Eur J Nucl Med Mol Imaging. 2014;41:1831-1844.

60. Kong G, Callahan J, Hofman MS, et al. High clinical and morphologic response using ${ }^{90}$ Y-DOTA-octreotate sequenced with ${ }^{177}$ Lu-DOTA-octreotate induction peptide receptor chemoradionuclide therapy (PRCRT) for bulky neuroendocrine tumours. Eur J Nucl Med Mol Imaging. 2017;44:476-489.

61. Hicks RJ, Kwekkeboom DJ, Krenning E, et al. ENETS consensus guidelines for the standards of care in neuroendocrine neoplasia: peptide receptor radionuclide therapy with radiolabeled somatostatin analogues. Neuroendocrinology. April 13, 2017 [Epub ahead of print].

62. Balon HR, Brown TL, Goldsmith SJ, et al. The SNM practice guideline for somatostatin receptor scintigraphy 2.0. J Nucl Med Technol. 2011;39:317324.

63. Mäcke HR, Smith-Jones P, Maina T, et al. New octreotide derivatives for in vivo targeting of somatostatin receptor-positive tumors for single photon emission computed tomography (SPECT) and positron emission tomography (PET). Horm Metab Res Suppl. 1993;27:12-17.

64. Press release: Advanced Accelerator Applications announces FDA approval of NETSPOT ${ }^{\text {TM }}$ (Somakit-TATE), a kit for the preparation of gallium Ga 68 dotatate for neuroendocrine tumor detection [press release]. June 2, 2016.
http://www.adacap.com/wp-content/uploads/2016/06/2016-06-02-PR-AAAFDA-approves-NETspot-for-diagnosis-of-NETs-FINAL-ENG-2.pdf. Accessed May 23, 2017.

65. Rahbar K, Ahmadzadehfar H, Kratochwil C, et al. German multicenter study investigating ${ }^{177} \mathrm{Lu}-\mathrm{PSMA}-617$ radioligand therapy in advanced prostate cancer patients. J Nucl Med. 2017;58:85-90.

66. Wild D, Fani M, Fischer R, et al. Comparison of somatostatin receptor agonist and antagonist for peptide receptor radionuclide therapy: a pilot study. $\mathrm{J}$ Nucl Med. 2014;55:1248-1252.

67. Ginj M, Zhang H, Eisenwiener KP, et al. New pansomatostatin ligands and their chelated versions: affinity profile, agonist activity, internalization, and tumor targeting. Clin Cancer Res. 2008;14:2019-2027.

68. Maina T, Cescato R, Waser B, et al. [ ${ }^{111}$ In-DOTA]LTT-SS28, a first pansomatostatin radioligand for in vivo targeting of somatostatin receptor-positive tumors. J Med Chem. 2014;57:6564-6571.

69. Nock BA, Maina T, Krenning EP, de Jong M. "To serve and protect": enzyme inhibitors as radiopeptide escorts promote tumor targeting. J Nucl Med. 2014;55: 121-127.

70. Bodei L, Kidd M, Modlin IM, et al. Measurement of circulating transcripts and gene cluster analysis predicts and defines therapeutic efficacy of peptide receptor radionuclide therapy (PRRT) in neuroendocrine tumors. Eur J Nucl Med Mol Imaging. 2016;43:839-851. 